\title{
Streambank Erosion and Ungulate Grazing Relationships
}

\author{
JOHN C. BUCKHOUSE, JON M. SKOVLIN, AND ROBERT W. KNIGHT
}

\section{Abstract}

Streambank erosional patterns have been studied for 3 years (1 year of calibration and 2 years of active grazing treatment) on the Starkey Experimental Forest and Range in the Blue Mountains of northeastern Oregon. Livestock grazing use at the rate of $3.2 \mathrm{ha} / \mathrm{AUM}$ ( 8 acres/AUM) has not accelerated streambank degradation on Meadow Creek. Most erosion occurred during wintering periods and this erosion has been independent of grazing season treatments. It appears that high runoff and occasional ice flows are the most significant factors in bank cutting on this stream.

We are entering a period in natural resource management where riparian zone considerations are drawing increased attention. This critical zone is often the focal point of watershed, livestock, wildlife, and fisheries management. While a fairly large volume of material has been published concerning the effects of livestock on aquatic environments (Meehan and Platts 1978), much of the material has been observational in nature. The need for detailed, technical information relating to ecological potentials as affected by land use encouraged us to develop this study in 1975. While a number of riparian relationships are being investigated in this five-year study, in this mid-project report we will deal only with the relationships among several different livestock grazing systems and streambank sloughing.

\section{Methods}

This inter-disciplinary study was established on Meadow Creek within the Starkey Experimental Forest and Range of northeastern Oregon. A stretch of approximately $6 \mathrm{~km}$ of the creek was divided into 19 different streamside areas, each of which was randomly assigned a specific grazing treatment. These 19 treatments represent replications of season-long, deferred rotation, rest rotation, and no (control) grazing (Table 1). In order to eliminate the confounding effects of different stocking intensity, all grazing treatments were based on the stocking rate of 3.2 ha/AUM.

Sixteen reference stakes were located within each treatment along the creek. Measurements recording the distance from the stake to the cut bank were made each fall following the grazing period and again during the spring following the ungrazed, overwintering period. Centimeters of streambank erosion were quantified from the 304 measurements which were collected at the end of each period.

\section{Results and Discussion}

Results were variable, as one might expect when looking at relatively short treatment periods. Nevertheless, on those treatments which showed significant differences $(P<.05)$ across grazed and nongrazing periods, more erosion generally took place during the nongrazed, over-winter period than during the grazing season. This apparent trend was without regard to grazing treatment, with the same phenomena taking place on the grazed and control areas (Table 2).

When one investigates the effect of treatment during any given time period, there is again a varied response (Table 3 ). For example, during the treatment years of 1976 and 1977 , one finds that

\footnotetext{
Authors are associate professor, Rangeland Resources Program, Oregon State University, Corvallis, Oregon 97331; research scientist, U.S. Dept. Agr. Forest Service, La Grande, Oregon 97850; and assistant professor, Texas A\&M University, College Station, Texas 77843 respectively.

This report was submitted as Technical Paper No. 5073. Oregon Agricultura Experiment Station, Corvallis, Oregon 97331. Support was provided by the Range and Wildlife Habitat Laboratory, Pacific Northwest Forest and Range Experiment Station, U.S. Dep. Agr. Forest Service and the Oregon Agricultural Experiment Station.

Manuscript received February 5, 1979.
}

Table 1. Streambank erosion observation periods and treatment identification.

\begin{tabular}{ccccccc}
\hline $\begin{array}{c}\text { Treat- } \\
\text { ment }\end{array}$ & $\begin{array}{c}\text { Time A } \\
(1975)\end{array}$ & $\begin{array}{c}\text { Time B } \\
(1975-6)\end{array}$ & $\begin{array}{c}\text { Time C } \\
(1976)\end{array}$ & $\begin{array}{c}\text { Time D } \\
(1976-7)\end{array}$ & $\begin{array}{r}\text { Time E } \\
(1977)\end{array}$ & $\begin{array}{c}\text { Time F } \\
(1977-8)\end{array}$ \\
\hline 1 & CP1 & OW & R & OW & R & OW \\
2 & CP & OW & R & OW & R & OW \\
3 & CP & OW & R & OW & SL & OW \\
4 & CP & OW & SL & OW & SL & OW \\
5 & CP & OW & RR(R) & OW & RR(G/R) & OW \\
6 & CP & OW & DR(G/R) & OW & DR(R/G) & OW \\
7 & CP & OW & SL & OW & SL & OW \\
8 & CP & OW & RR(G) & OW & RR(R/G) & OW \\
9 & CP & OW & C & OW & C & OW \\
10 & CP & OW & RR(G) & OW & RR(R/G) & OW \\
11 & CP & OW & SL & OW & SL & OW \\
12 & CP & OW & DR(G/R) & OW & DR(R/G) & OW \\
13 & CP & OW & RR(R) & OW & RR(G/R) & OW \\
14 & CP & OW & C & OW & C & OW \\
15 & CP & OW & mid & OW & mid & OW \\
16 & CP & OW & late & OW & late & OW \\
17 & CP & OW & C & OW & C & OW \\
18 & CP & OW & C & OW & C & OW \\
19 & CP & OW & C & OW & C & OW \\
\hline
\end{tabular}

${ }^{1}$ Treatment symbols are: $\mathrm{CP}=$ calibration period; $\mathrm{OW}=$ over-wintering period; $\mathrm{SL}=$ season long; $\mathrm{DR}=$ deferred rotation; $\mathrm{RR}=$ rest rotation; $\mathrm{G}=$ grazed; $\mathrm{R}=$ rest; $\mathrm{C}=$ control; mid=early August-early September; late=early September-mid October.

Table 2. Streambank erosion relationships of several grazing treatments over six time periods.

\begin{tabular}{ll}
\hline \hline & Treatment and time period \\
\hline Treatment I: & Treatment 10: \\
D, C, E, A, F, B & D, A, F, E, C, B \\
\hline (low) (high) & \\
Treatment 2: & Treatment 11: \\
A, C, F, E, D, B & A, D, E, C, F, B \\
\hline Treatment 3: & Treatment 12: \\
A, C, E, D, F, B & B, C, E, D, F, A \\
\hline Treatment 4: & Treatment 13: \\
C, A, F, E, D, B & A, E, C, D, F, B \\
\hline Treatment 5: & Treatment 14: \\
A, D, C, F, E, B & A, D, C, E, F, B \\
Treatment 6P & Treatment 15: \\
A, C, E, F, D, B & A, D, B, E, F, C \\
Treatment 7: & Treatment 16: \\
C, E, F, D, A, B & A, D, E, F, C, B. \\
\hline Treatment 8: & Treatment 17: \\
D, F, A, E, B, C & C, E, A, F, D, B \\
\hline Treatment 9: & Treatment 18: \\
A, E, C, F, D, B & C, A, F, E, D, B, D, B \\
\hline & \\
\hline
\end{tabular}

'Items underlined are not significantly different $(\boldsymbol{R}<.05)$ from each other 
Table 3. Streambank erosion relationships of grazing treatments during the grazing season and over-wintering periods.

Time A: (calibration period, 1975) ${ }^{\mathrm{I}}$

$15,11,16,19,513,9,10,14,2,3,61,4,8,17,18,12,7$

(low)

(high)

Time B: (over-wintering period, 1975, 1976)

$15,12,14,1,10,8,11,5,9,16,18,19,17,7,2,3,6,4,13$

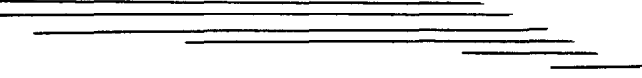

Time C: (grazing season, 1976)

$17,19,18,1,9,4,14,2,3,5,13,12,16,10,11,7,6,15,8$

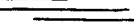

Time D: (over-wintering period, 1976-77)

$\underline{15,10,1,14,8,16,9,5,11,6,13,12,19,17,18,7,3,4,2}$

Time E: (grazing season, 1977)

$9,17,1,10,14,15,8,13,16,2,6,11,3,18,12,19,5,7,4$

Time F: (cover-wintering, 1977-78)

$12,10,9,8,2,16,19,5,14,6,18,1,13,17,15,4,11,7,3$

Items underlined are not significantly different $(P<.05)$ from another. Bold items indicate grazed treatments.

season-long grazing resulted in erosion rates that varied from 1 st to 14th position out of the erosional continua of 19 treatments. While the erosion rates associated with the several season-long treatments tended to be expressed at the high end of the erosional scale, they fell within the natural variance of the system and no significant pattern was evident. If one looks at the rest rotation treatments, a similar situation exists, with their erosion rates falling between 1st and 18th position. The ungrazed group during these same time periods varied from 1st to 19 th position. These results indicate that there were no particular relationships between streambank erosion and the various grazing treatments during the given time periods. Hayes (1978) found similar relationships in a high mountain area of Idaho. His results indicated that grazing (rest-rotation) did not significantly accelerate channel movement and that the occurrence of degradation during spring discharge along ungrazed streambanks was significantly greater than degradation occurring along grazed streambanks.

Since it is probable that the erosional sequence is a combination of grazing use and over-winter, annual values depicting total erosional loss were investigated. The annual erosional losses of the grazed units were compared to those of the ungrazed units for the years of 1976 and 1977. In 1976 the mean annual erosional loss from the grazed units was $16 \mathrm{~cm}$, while the ungrazed units lost 11 $\mathrm{cm}$. In 1977 the mean annual loss was $14 \mathrm{~cm}$ from the grazed treatments and $8 \mathrm{~cm}$ from the ungrazed group. While in both cases the grazed units showed higher mean annual erosional losses, the differences were not significant $(P<.10)$.

\section{Conclusions}

The results of a grazing study in northeastern Oregon, after 1 year of calibration and 2 years of grazing management treatments, indicated that no significant patterns of accelerated streambank deterioration had occurred due to moderate livestock grazing ( 3.2 ha/AUM). Most bank cutting losses in this system were apparently associated with over-wintering periods when high water, ice flow, and channel physiognomy are critical.

\section{Literature Cited}

Hayes, F.A. 1978. Streambank stability and meadow condition in relation to livestock grazing in mountain meadows of central Idaho. M.S. Thesis. Univ. of Idaho. Moscow, Id .91 p.

Meehan, W.R. and W.S. Platts. 1978. Livestock grazing and the aquatic environment. J. Soil and Water Conserv. 33:274-278. 